Clive M. Brown · Matthias Dütsch · Susanne Öhring

Bernhard Neundörfer · Max J. Hilz

\title{
Cerebral autoregulation is compromised during simulated fluctuations in gravitational stress
}

Accepted: 3 September 2003 / Published online: 22 October 2003

(c) Springer-Verlag 2003

\begin{abstract}
Gravity places considerable stress on the cardiovascular system but cerebral autoregulation usually protects the cerebral blood vessels from fluctuations in blood pressure. However, in conditions such as those encountered on board a high-performance aircraft, the gravitational stress is constantly changing and might compromise cerebral autoregulation. In this study we assessed the effect of oscillating orthostatic stress on cerebral autoregulation. Sixteen (eight male) healthy subjects [aged 27 (1) years] were exposed to steady-state lower body negative pressure (LBNP) at -15 and $-40 \mathrm{mmHg}$ and then to oscillating LBNP at the same pressures. The oscillatory LBNP was applied at 0.1 and $0.2 \mathrm{~Hz}$. We made continuous recordings of RR-interval, blood pressure, cerebral blood flow velocity (CBFV), respiratory frequency and end-tidal $\mathrm{CO}_{2}$. Oscillations in mean arterial pressure (MAP) and CBFV were assessed by autoregressive spectral analysis. Respiration was paced at $0.25 \mathrm{~Hz}$ to avoid interference from breathing. Steady-state LBNP at $-40 \mathrm{mmHg}$ significantly increased low-frequency (LF, $0.03-0.14 \mathrm{~Hz})$ powers of MAP $(P<0.01)$ but not of CBFV. Oscillatory $0.1 \mathrm{~Hz}$ LBNP (0 to $-40 \mathrm{mmHg}$ ) significantly increased the LF power of MAP to a similar level as steady-state LBNP but also resulted in a significant increase in the $\mathrm{LF}$ power of $\mathrm{CBFV}$ $(P<0.01)$. Oscillatory LBNP at $0.2 \mathrm{~Hz}$ induced oscillations in MAP and CBFV at $0.2 \mathrm{~Hz}$. Cross-spectral analysis showed that the transfer of LBNP-induced oscillations in MAP onto the CBFV was significantly
\end{abstract}

C. M. Brown $(\varangle) \cdot$ M. Dütsch $\cdot$ S. Öhring $\cdot$ B. Neundörfer M. J. Hilz

Autonomic Laboratory, Dept. of Neurology,

University of Erlangen-Nuremberg, Germany

E-mail: CliveBrown750@hotmail.com

Tel.: + 41-26-3008600

Fax: + 41-26-3009734

C. M. Brown

Dept. of Physiology, University of Fribourg, Ch. du Musée 5, 1700 Fribourg, Switzerland greater at $0.2 \mathrm{~Hz}$ than at $0.1 \mathrm{~Hz}(P<0.01)$. These results show that the ability of the cerebral vessels to modulate fluctuations in blood pressure is compromised during oscillatory compared with constant gravitational stress. Furthermore, this effect seems to be more pronounced at higher frequencies of oscillatory stress.

Keywords Cerebral autoregulation - Gravity - LBNP • Orthostasis $\cdot$ Sympathetic nervous system

\section{Introduction}

Cerebral autoregulation is the phenomenon by which cerebral blood flow remains near-constant despite changes in systemic blood pressure, provided that mean blood pressure remains within certain limits, usually $50-150 \mathrm{mmHg}$ (Aaslid et al. 1989). The characteristics of cerebral autoregulation have been studied during a variety of stimulations including deep breathing (Diehl et al. 1995), the Valsalva manoeuvre (Tiecks et al. 1996), thigh cuff deflation (Aaslid et al. 1989), head-down tilting (Heckmann et al. 1999), ergometric exercise (Heckmann et al. 2000), orthostatic stress (Carey et al. 2001; Lipsitz et al. 2000) and squatting (Birch et al. 1995).

Gravity places considerable stress on the cardiovascular system due to the sequestration of blood to the lower part of the body (Brown and Hainsworth 1999). During steady-state orthostasis, there is a sympathetically mediated increase in the power of low-frequency (LF, $0.03-0.14 \mathrm{~Hz}$ ) oscillations in blood pressure (Cooke et al. 1999) that is not transferred onto the cerebral blood flow (Lipsitz et al. 2000), confirming the integrity of cerebral autoregulation. However, stimuli such as repetitive squatting or tilting can induce large oscillations in cerebral blood flow (Birch et al. 1995; Hughson et al. 2001). Therefore, the cerebral vessels 
might respond differently to periodical rather than steady-state orthostatic stress. This could be of importance in situations where there are sudden, rapid changes in gravitational stress such as those encountered on board a high-performance aircraft ("push-pull" effect). Rapidly alternating gravitational stress increases the risk of syncope compared to steady-state gravitational stress (Banks et al. 1994) and might be a contributing factor to G-induced loss of consciousness (G-LOC) in aviators. After repeated exposure to micro- and hypergravity induced by parabolic flight, there is a reduction in cerebral blood flow with a higher risk of syncope (Schlegel et al. 2001; Serrador et al. 2000b). However, the response of the cerebral blood vessels to blood pressure fluctuations during alternating gravitational stress at different frequencies is not yet clear.

Therefore, the aim of our study was to assess the effects of periodical gravitational stress on the regulation of cerebral blood flow velocity. We simulated gravitational stress by application of oscillatory lower body negative pressure (LBNP). To determine whether the frequency of the alternating gravitational stress influences autoregulation, we compared the effects of LBNP at $0.1 \mathrm{~Hz}$ (6 cycles/min) and $0.2 \mathrm{~Hz}(12$ cycles $/ \mathrm{min})$. Responses of cerebral blood flow during oscillating LBNP were also compared with those during steady-state LBNP.

Fig. 1 Example of time series of mean arterial pressure (MAP), cerebral blood flow velocity (CBFV) and pressure within the lowerbody negative presssure (LBNP) chamber from one subject during baseline and oscillating LBNP (0 to $-40 \mathrm{mmHg}$ ) at 0.1 and $0.2 \mathrm{~Hz}$

\section{Methods}

Subjects

Sixteen healthy young adults (eight male) aged 25-30 years [mean 27 (1) years] participated in the study. None had any history of cardiovascular or neurological disorders, and none was taking any medication. All the participants were asked to refrain from caffeine on the day of the experimental procedures and to eat nothing for at least $3 \mathrm{~h}$ before the tests. The mean height of the subjects was 176 (3) $\mathrm{cm}$ and their weight was 72 (3) $\mathrm{kg}$. Informed consent was obtained from each subject and the procedures received approval from the local ethics committee.

\section{Procedures}

Studies were performed during steady-state LBNP at -15 and $-40 \mathrm{mmHg}$, then during oscillating 0.1 and $0.2 \mathrm{~Hz}$ LBNP. The oscillating LBNP was applied at two levels: 0 to $-15 \mathrm{mmHg}$ and 0 to $-40 \mathrm{mmHg}$.

All measurements were performed with the subjects lying in a supine position with their lower body enclosed in an LBNP chamber with footboard support, sealed at the level of the iliac crests. Pressure within the chamber was monitored and recorded by a pressure transducer (Hugo-Sachs Elektronik, March, Germany) and could be lowered with a variable vacuum pump. After at least $40 \mathrm{~min}$ of supine rest to allow for cardiovascular stability, 4-minlong recordings were made during steady-state LBNP applied at 0 , -15 and $-40 \mathrm{mmHg}$.

Following an interval of at least $15 \mathrm{~min}$, 4-min-long recordings were made during LBNP of $0 \mathrm{mmHg}$ (baseline), oscillating lowlevel LBNP $(0$ to $-15 \mathrm{mmHg})$ at $0.1 \mathrm{~Hz}$ and $0.2 \mathrm{~Hz}$, then during oscillating high-level LBNP (0 to $-40 \mathrm{mmHg}$ ) at $0.1 \mathrm{~Hz}$ and $0.2 \mathrm{~Hz}$. The oscillatory LBNP was accomplished by a control unit regulating an on-off vacuum system resulting in a pressure wave as shown in Fig. 1.

Throughout testing, breathing was paced at $0.25 \mathrm{~Hz}$ (15 breaths/min) by combined auditory and visual stimuli. The respiratory rate of $0.25 \mathrm{~Hz}$ was chosen to ensure that blood pres-
MAP (mmHg)

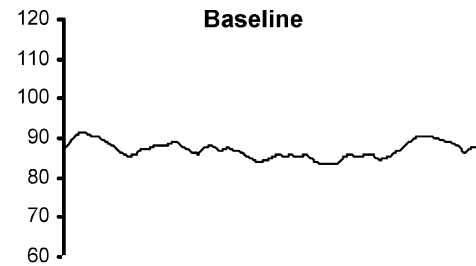

$\operatorname{CBFV}\left(\mathrm{cm} \mathrm{s}^{-1}\right)$

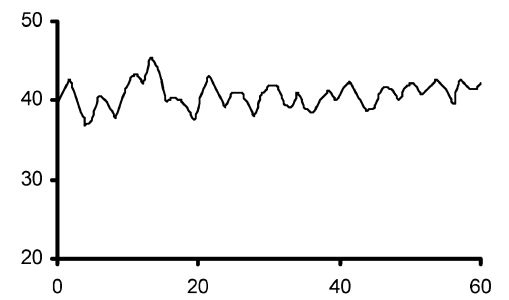

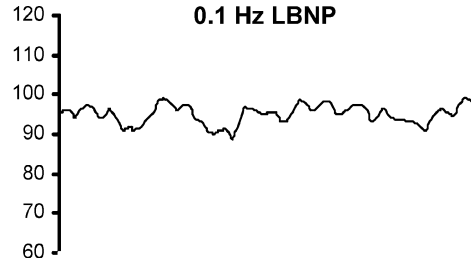
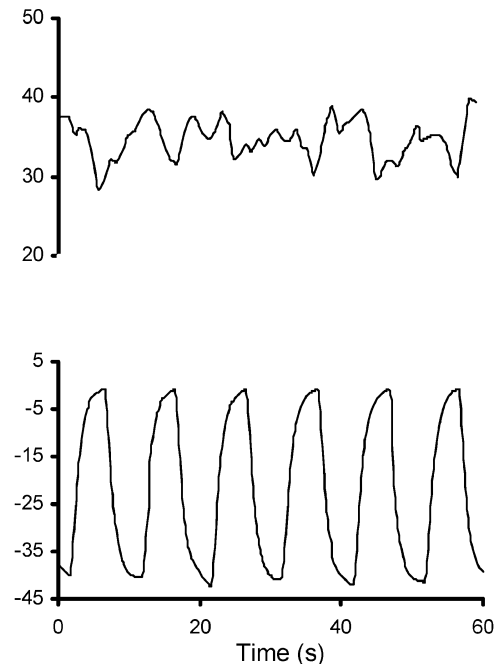
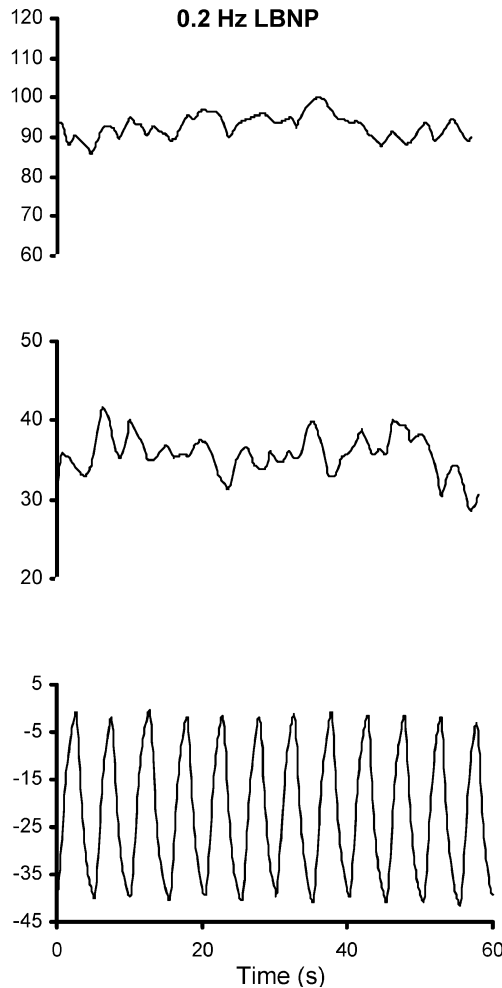

LBNP (mmHg) 
sure fluctuations in the low-frequency range or at the LBNP stimulation frequencies were not influenced by the mechanical effects of breathing. Prior to the procedures, each subject was trained in pacing their breathing at $0.25 \mathrm{~Hz}$, trying to avoid hyperventilation. End-tidal $\mathrm{CO}_{2}\left(\mathrm{PETCO}_{2}\right)$ was monitored online by an investigator and the subject was subsequently instructed to alter his/her depth of breathing accordingly.

We continuously recorded RR-intervals (5-lead ECG) and blood pressure by non-invasive radial arterial tonometry (ColinPilot, Colin Medical, San Antonio, Tex., USA). Respiration was monitored by electrical inductance plethysmography (Respitrace Calibrator, Ambulatory Monitoring, Ardsley, N.Y., USA). Cerebral blood flow velocity (CBFV) was measured using transcranial Doppler ultrasonography (Multidop X4, DWL, Sipplingen, Germany). The left or right middle cerebral artery was insonated at a depth of 35-55 $\mathrm{mm}$ using a $2 \mathrm{MHz}$ probe, and the probe was fixed in place with a headband. Beat-to-beat values of systolic, diastolic and mean velocity were recorded. Expiratory air was sampled via a nasal cannula and end-tidal $\mathrm{CO}_{2}$ measured by infrared absorption (Colin-Pilot, Colin Medical, San Antonio, Tex., USA).

Data acquisition and analysis

Data were digitized by an analogue-to-digital converter at a sampling rate of $300 \mathrm{~Hz}$ and fed to a Macintosh PowerBook computer (Apple, USA). A computer program identified all the QRS complexes in each sequence and then located the peak of each $R$ wave. Time series were obtained of RR-intervals, blood pressure (systolic, diastolic and mean), CBFV (systolic, diastolic and mean), respiration, $P \mathrm{ETCO}_{2}$ and pressures within the LBNP chamber.

Fluctuations in the recorded signals were characterized by autoregressive power spectrum analysis, which allows for identification of the frequencies and powers of the relevant oscillations with relatively small amounts of data (Bernardi et al. 1995; Brown et al. 2002). We considered oscillations in the low-frequency (LF, 0.03$0.14 \mathrm{~Hz}$ ) and high-frequency $(\mathrm{HF}, 0.15-0.40 \mathrm{~Hz})$ bands. We assessed the oscillatory components corresponding to the frequencies of oscillatory LBNP as the area under the spectral curve that was centered at the frequency of stimulation $(0.10$ or $0.20 \mathrm{~Hz})$ (Bernardi et al. 1995). We applied a model order of 12 for recordings made during the steady-state and $0.1 \mathrm{~Hz}$ oscillatory LBNP. For analysis of the $0.2 \mathrm{~Hz}$ LBNP we applied a model order of 20 to distinguish between the LBNP-induced cardiovascular oscillations at $0.2 \mathrm{~Hz}$ and the breathing-induced oscillations at $0.25 \mathrm{~Hz}$.

To assess the transmission of oscillations in MAP onto the CBFV during oscillatory LBNP we used cross-spectral analysis, which allows for comparison of pairs of oscillating signals. The coherence function ranges from 0 to 1 and refers to the amount of linear coupling between two oscillations. Coherence values $>0.5$ are considered significant (Bernardi et al. 1995). To assess the transfer of MAP oscillations onto the CBFV, we calculated the MAP-CBFV gain as the square root of the ratio of the power of CBFV oscillations to the power of MAP oscillations, at the relevant frequency. This gives a value in $\mathrm{cm} \cdot \mathrm{s}^{-1} \mathrm{mmHg}{ }^{-1}$ and is analogous to the alpha-index that is frequently used to assess baroreflex sensitivity (Pitzalis et al. 1998). In addition, we assessed the phase relation between oscillations in MAP and CBFV. The phase relation was expressed in radians with a positive value indicating that MAP leads CBFV and a negative value indicating that $\mathrm{CBFV}$ leads MAP.

Statistical analysis

All values reported are means (SEM), unless otherwise stated. Time-domain and frequency-domain responses to each level of LBNP were evaluated using the non-parametric Friedman test ANOVA with Dunn post-hoc analysis where a significant $P$-value was found. Comparison of cerebral autoregulation during $0.1 \mathrm{~Hz}$ and $0.2 \mathrm{~Hz}$ LBNP was made by Wilcoxin test. $P$ values $<0.05$ were considered statistically significant.

\section{Results}

\section{Steady-state LBNP}

Mean cardiovascular variables and their spectral characteristics recorded during steady-state LBNP are summarized in Table 1. LBNP at -15 and $-40 \mathrm{mmHg}$ resulted in significantly increased mean and diastolic blood pressures $(P<0.01)$ from baseline values, but decreased systolic and mean CBFV $(P<0.01)$. RR-interval
Table 1 Effects of steady-state lower body negative pressure $(L B N P)$ on mean cardiovascular variables and their spectral characteristics. (BP Blood pressure, $C B F V$ cerebral blood flow velocity, $L F$ low frequency, $H F$ high frequency)

Significant changes from baseline are denoted by $*(P<0.05)$ or ** $(P<0.01)$

\begin{tabular}{|c|c|c|c|}
\hline \multirow[t]{2}{*}{ Variable } & \multicolumn{3}{|c|}{ LBNP level (mmHg) } \\
\hline & 0 (Baseline) & 15 & 40 \\
\hline RR-interval (ms) & $944(32)$ & $942(34)$ & $819(34)^{* *}$ \\
\hline RR-interval LF power $\left(\mathrm{ms}^{2}\right)$ & $740(142)$ & $685(154)$ & $763(218)$ \\
\hline RR-interval HF power $\left(\mathrm{ms}^{2}\right)$ & $874(240)$ & $1066(446)$ & $233(67)^{* *}$ \\
\hline Systolic BP (mmHg) & $114(2)$ & $119(4)^{*}$ & $116(3)$ \\
\hline Systolic BP LF power $\left(\mathrm{mmHg}^{2}\right)$ & $1.39(0.21)$ & $2.37(0.66)$ & $5.72(1.49)^{* *}$ \\
\hline Systolic BP HF power $\left(\mathrm{mmHg}^{2}\right)$ & $1.12(0.15)$ & $1.51(0.38)$ & $2.57(0.89)$ \\
\hline Mean BP (mmHg) & $80(2)$ & $85(3)^{*}$ & $86(2)^{* *}$ \\
\hline Mean BP LF power $\left(\mathrm{mmHg}^{2}\right)$ & $1.01(0.16)$ & $3.01(1.07)$ & $4.58(1.06)^{* *}$ \\
\hline Mean BP HF power $\left(\mathrm{mmHg}^{2}\right)$ & $0.24(0.06)$ & $0.35(0.07)$ & $0.82(0.24)^{*}$ \\
\hline Diastolic BP $(\mathrm{mmHg})$ & $64(3)$ & $69(2)^{*}$ & $72(2)^{* *}$ \\
\hline Diastolic BP LF power $\left(\mathrm{mmHg}^{2}\right)$ & $1.26(0.36)$ & $1.69(0.57)$ & $4.67(1.06)^{* *}$ \\
\hline Diastolic BP HF power $\left(\mathrm{mmHg}^{2}\right)$ & $0.40(0.08)$ & $0.65(0.25)$ & $0.92(0.22)$ \\
\hline Systolic CBFV $\left(\mathrm{cm} \mathrm{s}^{-1}\right)$ & $84(5)$ & $79(5)$ & $72(5)^{* * *}$ \\
\hline Systolic CBFV LF power $\left(\mathrm{cm} \mathrm{s}^{-2}\right)$ & $2.77(0.42)$ & $3.97(1.11)$ & $3.43(0.61)$ \\
\hline Systolic CBFV HF power $\left(\mathrm{cm} \mathrm{s}^{-2}\right)$ & $3.42(0.51)$ & $3.21(0.54)$ & $4.79(1.36)$ \\
\hline Mean CBFV $\left(\mathrm{cm} \mathrm{s}^{-1}\right)$ & $47(4)$ & $44(3)$ & $41(4)^{* *}$ \\
\hline Mean CBFV LF power $\left(\mathrm{cm} \mathrm{s}^{-2}\right)$ & $2.05(0.38)$ & $2.09(0.47)$ & $2.80(0.81)$ \\
\hline Mean CBFV HF power $\left(\mathrm{cm} \mathrm{s}^{-2}\right)$ & $1.25(0.27)$ & $1.59(0.44)$ & $2.34(0.63)$ \\
\hline Diastolic CBFV $\left(\mathrm{cm} \mathrm{s}^{-1}\right)$ & $28(3)$ & $26(3)$ & $27(3)$ \\
\hline Diastolic CBFV LF power $\left(\mathrm{cm} \mathrm{s}^{-2}\right)$ & $2.12(0.49)$ & $1.89(0.49)$ & $3.99(1.34)$ \\
\hline Diastolic CBFV HF power $\left(\mathrm{cm} \mathrm{s}^{-2}\right)$ & $1.09(0.27)$ & $1.40(0.47)$ & $1.76(0.42)$ \\
\hline$P \mathrm{ETCO}_{2}$ & $35.5(0.9)$ & $35.0(1.1)$ & $31.7(0.9)^{* *}$ \\
\hline
\end{tabular}


was significantly decreased $(P<0.01)$ during $-40 \mathrm{mmHg}$ but not $-15 \mathrm{mmHg}$ LBNP. $P \mathrm{ETCO}_{2}$ was significantly decreased at the $-40 \mathrm{mmHg}$ LBNP level compared to baseline.

LBNP at $-40 \mathrm{mmHg}$ significantly increased $(P<0.01)$ the LF $(0.03-0.14 \mathrm{~Hz})$ power of blood pressure (systolic, diastolic and mean) but did not significantly change the LF power of CBFV.

\section{Oscillating $(0.1 \mathrm{~Hz}) \mathrm{LBNP}$}

Figure 1 shows an example of a time-series of MAP and CBFV recorded during baseline, $0.1 \mathrm{~Hz}$ LBNP and $0.2 \mathrm{~Hz}$ LBNP (0 to $-40 \mathrm{mmHg}$ ). Mean RR-intervals, blood pressures and cerebral blood velocities with their spectral characteristics recorded during $0.1 \mathrm{~Hz}$ oscillating LBNP are summarized in Table 2. Oscillating LBNP significantly increased $(P<0.05)$ blood pressure and decreased $(P<0.01)$ CBFV. Mean RR-intervals were unaffected by the 0 to $-15 \mathrm{mmHg}$ LBNP oscillations at $0.1 \mathrm{~Hz}$ but were significantly $(P<0.01)$ decreased by the 0 to $-40 \mathrm{mmHg}$ LBNP stimulation. When the 0 to $-40 \mathrm{mmHg}$ oscillatory stimulus was applied, $\mathrm{PETCO}_{2}$ was 33 (1.2) $\mathrm{mmHg}$ during the LBNP "off" periods but decreased to $30.0(1.0) \mathrm{mmHg}$ during the $-40 \mathrm{LBNP}$ "on" periods. $\mathrm{PETCO}_{2}$ did not oscillate during the 0 to $-15 \mathrm{mmHg}$ LBNP application.

Oscillating $0.1 \mathrm{~Hz}$ LBNP at 0 to $-15 \mathrm{mmHg}$ significantly increased $(P<0.05)$ the LF powers of RR-interval, diastolic and mean blood pressures, but did not significantly change the LF powers of CBFV. However, oscillating $0.1 \mathrm{~Hz}$ LBNP at 0 to $-40 \mathrm{mmHg}$ resulted in significant increases $(P<0.01)$ in the LF power of systolic, diastolic and mean blood pressures, and in systolic, diastolic and mean CBFV. Spectral analysis confirmed that each subject's respiration rate remained at $0.25 \mathrm{~Hz}$ throughout the LBNP stimulations.

We compared responses during oscillating LBNP at $0.1 \mathrm{~Hz}$ with responses obtained during steady-state LBNP at the same level (Fig. 2). Low- and high-frequency oscillations in mean blood pressure were not significantly different during oscillatory compared with steady-state LBNP. However, the LF oscillations in CBFV were significantly enhanced during $0.1 \mathrm{~Hz}$ oscillatory compared with steady-state LBNP.

\section{Oscillating $(0.2 \mathrm{~Hz}) \mathrm{LBNP}$}

Oscillating $0.2 \mathrm{~Hz}$ LBNP induced $0.2 \mathrm{~Hz}$ oscillations in RR-interval, systolic, diastolic and mean blood pressures, and systolic, diastolic and mean cerebral blood flow velocities. These oscillations were distinct from the breathing-induced oscillations at $0.25 \mathrm{~Hz}$. The powers of the LBNP-induced $0.2 \mathrm{~Hz}$ oscillations are summarized in Table 3. The $0.2 \mathrm{~Hz}$ oscillations in blood pressure and CBFV were significantly enhanced $(P<0.01)$ when the LBNP was applied at 0 to $-40 \mathrm{mmHg}$ as compared with 0 to $-15 \mathrm{mmHg}$.

\section{Cross-spectral analysis}

We performed a cross-spectral analysis of the LF and $\mathrm{HF}$ oscillations in mean CBFV and in MAP in those
Table 2 Mean cardiovascular variables recorded during baseline and during $0.1 \mathrm{~Hz}$ oscillatory lower body negative pressure $(L B N P)$. (BP Blood pressure, $C B F V$ cerebral blood flow velocity, $L F$ low frequency, $H F$ high frequency)

Significant differences from baseline are denoted by $*(P<0.05), * *(P<0.01)$. Significant differences from steadystate LBNP are denoted by $\dagger$ $(P<0.05)$ or $\uparrow \dagger(P<0.01)$

\begin{tabular}{|c|c|c|c|}
\hline \multirow[t]{3}{*}{ Variable } & \multirow{3}{*}{$\begin{array}{l}\text { Baseline } \\
0\end{array}$} & \multicolumn{2}{|l|}{$0.1 \mathrm{~Hz}$} \\
\hline & & \multicolumn{2}{|c|}{ LBNP level (mmHg) } \\
\hline & & 0 to -15 & 0 to -40 \\
\hline RR-interval (ms) & $1010(34)$ & $992(32) \dagger \dagger$ & $948(32)^{* * \dagger \dagger}$ \\
\hline RR-interval LF power $\left(\mathrm{ms}^{2}\right)$ & $667(124)$ & $1383(301)^{* \dagger \dagger}$ & $1379(299)^{*}$ \\
\hline RR-interval HF power $\left(\mathrm{ms}^{2}\right)$ & $1867(695)$ & $1754(582)$ & $1316(372) \dagger \dagger$ \\
\hline Systolic BP (mmHg) & $114(3)$ & $121(4) * *$ & $119(4)^{*}$ \\
\hline Systolic BP LF power $\left(\mathrm{mmHg}^{2}\right)$ & $1.07(0.22)$ & $2.28(0.48)^{*}$ & $4.03(1.31)^{* *}$ \\
\hline Systolic BP HF power $\left(\mathrm{mmHg}^{2}\right)$ & $1.10(0.20)$ & $1.37(0.23)$ & $1.69(0.25)^{*}$ \\
\hline Mean BP $(\mathrm{mmHg})$ & $82(2)$ & $85(2)^{* *}$ & $84(2)^{* *}$ \\
\hline Mean BP LF power $\left(\mathrm{mmHg}^{2}\right)$ & $0.79(0.21)$ & $2.14(0.55)^{* *}$ & $3.30(0.56)^{* *}$ \\
\hline Mean BP $\mathrm{HF}$ power $\left(\mathrm{mmHg}^{2}\right)$ & $0.39(0.18)$ & $0.38(0.07)$ & $0.45(0.07)^{* *}$ \\
\hline Diastolic BP $(\mathrm{mmHg})$ & $65(2)$ & $68(2)^{*}$ & $68(2)$ \\
\hline Diastolic BP LF power $\left(\mathrm{mmHg}^{2}\right)$ & $0.94(0.27)$ & $2.30(0.42)^{* \dagger}$ & $3.36(0.50)^{* *}$ \\
\hline Diastolic BP HF power $\left(\mathrm{mmHg}^{2}\right)$ & $0.63(0.18)$ & $0.69(0.21)$ & $0.57(0.13)$ \\
\hline Systolic CBFV $\left(\mathrm{cm} \mathrm{s}^{-1}\right)$ & $88(5)$ & $82(5)^{* *}$ & $78(5)^{* *}$ \\
\hline Systolic CBFV LF power $\left(\mathrm{cm} \mathrm{s}^{-2}\right)$ & $1.52(0.34)$ & $3.57(0.61)$ & $10.17(1.92)^{* * \dagger \dagger}$ \\
\hline Systolic CBFV HF power $\left(\mathrm{cm} \mathrm{s}^{-2}\right)$ & $2.73(0.57)$ & $2.55(0.44)$ & $3.40(0.69)$ \\
\hline Mean CBFV $\left(\mathrm{cm} \mathrm{s}^{-1}\right)$ & $50(4)$ & $45(4)$ & $41(4)^{* *}$ \\
\hline Mean CBFV LF power $\left(\mathrm{cm} \mathrm{s}^{-2}\right)$ & $1.60(0.22)$ & $2.96(0.63)$ & $5.24(1.15)^{* * \dagger}$ \\
\hline Mean CBFV HF power $\left(\mathrm{cm} \mathrm{s}^{-2}\right)$ & $1.32(0.27)$ & $1.59(0.31)$ & $1.62(0.36)$ \\
\hline Diastolic CBFV $\left(\mathrm{cm} \mathrm{s}^{-1}\right)$ & $30(3)$ & $27(3)$ & $23(3)^{* *+\dagger}$ \\
\hline Diastolic BP CBFV power $\left(\mathrm{cm} \mathrm{s}^{-2}\right)$ & $1.32(0.23)$ & $3.09(0.66) \dagger$ & $5.74(1.02) \dagger \dagger$ \\
\hline Diastolic BP CBFV power $\left(\mathrm{cm} \mathrm{s}^{-2}\right)$ & $1.25(0.35)$ & $1.39(0.36)$ & $1.57(0.46)$ \\
\hline
\end{tabular}


subjects who had significant $(>0.5)$ coherence between these oscillations at the relevant frequency.

In order to include the maximal number of subjects with sufficient coherence, we only performed the cross-
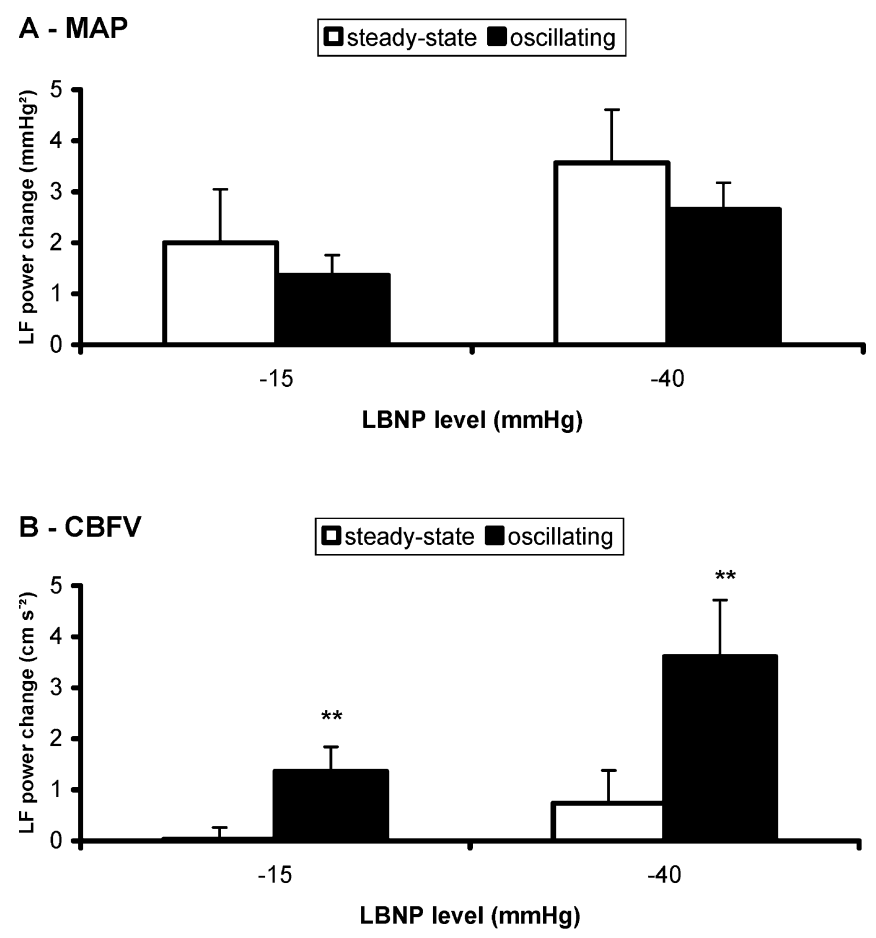

Fig. 2 Comparison of the effects of steady-state and oscillating LBNP on low-frequency $(L F)$ powers of mean arterial pressure $(M A P)$ and cerebral blood flow velocity $(C B F V)$. Responses are expressed as the change from baseline LF powers. The effect of oscillating LBNP on the LF power of MAP was not significantly different from steady-state LBNP. However, the response of LF power of CBFV was significantly enhanced when oscillating, as compared with when steady-state LBNP was applied $\left.{ }^{* * *} P<0.01\right)$

Table 3 Cardiovascular responses during $0.2 \mathrm{~Hz}$ LBNP. (BP Blood pressure, $C B F V$ cerebral blood flow velocity)

\begin{tabular}{lll}
\hline Variable & \multicolumn{2}{l}{ LBNP level $(\mathrm{mmHg})$} \\
\cline { 2 - 3 } & 0 to -15 & 0 to -40 \\
\hline RR-interval (ms) & $972(33)$ & $943(32)$ \\
RR-interval 0.2 Hz power $\left(\mathrm{ms}^{2}\right)$ & $737(355)$ & $1021(452)$ \\
Systolic BP $(\mathrm{mmHg})$ & $119(3)$ & $119(3)$ \\
Systolic BP 0.2 Hz power $\left(\mathrm{mmHg}^{2}\right)$ & $1.07(0.25)$ & $1.37(0.31)$ \\
Mean BP (mmHg) & $84(2)$ & $85(2)$ \\
Mean BP 0.2 Hz power $\left(\mathrm{mmHg}^{2}\right)$ & $0.38(0.06)$ & $0.96(0.18)^{* *}$ \\
Diastolic BP $(\mathrm{mmHg})$ & $68(2)$ & $69(2)$ \\
Diastolic BP 0.2 Hz power $\left(\mathrm{mmHg}^{2}\right)$ & $0.47(0.10)$ & $1.07(0.16)^{* *}$ \\
Systolic CBFV $(\mathrm{cm} \mathrm{s}$ ) & $80(5)$ & $77(5)$ \\
Systolic CBFV 0.2 Hz power $\left(\mathrm{cm} \mathrm{s}^{-2}\right)$ & $1.77(0.27)$ & $6.23(1.67)^{* *}$ \\
Mean CBFV $\left(\mathrm{cm} \mathrm{s}^{-1}\right)$ & $43(4)$ & $41(4)$ \\
Mean CBFV 0.2 Hz power $\left(\mathrm{cm} \mathrm{s}^{-2}\right)$ & $0.89(0.14)$ & $3.23(0.85)^{* *}$ \\
Diastolic CBFV $\left(\mathrm{cm} \mathrm{s}^{-1}\right)$ & $43(4)$ & $41(4)$ \\
Diastolic CBFV 0.2 Hz power $\left(\mathrm{cm} \mathrm{s}^{-2}\right)$ & $0.91(0.21)$ & $3.86(1.15)^{* *}$ \\
\hline
\end{tabular}

$*(P<0.05)$ and $* *(P<0.01)$ denote significant differences between the 0 to $-15 \mathrm{mmHg}$ and the 0 to $-40 \mathrm{mmHg}$ levels spectral analysis during LBNP at the $-40 \mathrm{mmHg}$ level (or 0 to $-40 \mathrm{mmHg}$ level).

Table 4 shows the cross-spectral characteristics of the steady-state and the $0.1 \mathrm{~Hz}$ oscillatory LBNP. There was a consistently negative phase shift between MAP and CBFV (i.e. oscillations in CBFV were leading those in MAP). The MAP-CBFV gain was significantly increased during the oscillatory LBNP, indicating an enhanced transmission of LF oscillations in MAP onto the $\mathrm{CBFV}$. In the HF range, the phase relation between oscillations in MAP and CBFV was close to zero, indicating that these oscillations were approximately in phase. The gain in the HF range was less during oscillating LBNP but not significantly so.

Table 5 shows the results of the cross-spectral analysis during oscillating LBNP applied at $0.1 \mathrm{~Hz}$ compared with $0.2 \mathrm{~Hz}$. Of the 16 subjects, 15 had significant coherence $(>0.5)$ between the MAP and CBFV oscillations at the stimulating frequency during both 0.1 and $0.2 \mathrm{~Hz}$ oscillating at 0 to $-40 \mathrm{mmHg}$. In these subjects the MAP-CBFV gain at the stimulating frequency was significantly greater $(P<0.01)$ when the LBNP was applied at $0.2 \mathrm{~Hz}$ than at $0.1 \mathrm{~Hz}$ (Fig. 3).

Table 4 Cross-spectral analysis during steady-state and $0.1 \mathrm{~Hz}$ oscillating LBNP. Values refer to the cross-spectral analysis with mean arterial pressure $(M A P)$ as the input signal and mean cerebral blood flow velocity $(C B F V)$ as the output signal. The negative phase in the low-frequency $(L F)$ range indicates that CBFV leads MAP. Gain is the MAP-CBFV gain. ( $H F$ High frequency)

\begin{tabular}{lllll}
\hline & & $\begin{array}{l}\text { Steady-state } \\
\text { LBNP }\end{array}$ & $\begin{array}{l}\text { Oscillating } \\
\text { LBNP }\end{array}$ & $n$ \\
\hline LF & Coherence & $0.72(0.05)$ & $0.80(0.05)$ & \\
& Phase (rad) & $-1.13(0.07)$ & $-1.15(0.22)$ & 10 \\
& Gain & $0.88(0.15)$ & $1.36(0.20)^{*}$ & \\
& $\left(\mathrm{cms}^{-1} \mathrm{mmHg}^{-1}\right)$ & & & \\
HF (0.25 Hz) & Coherence & $0.90(0.03)$ & $0.87(0.04)$ & \\
& Phase (rad) & $0.03(0.08)$ & $-0.16(0.08)$ & 14 \\
& $\begin{array}{l}\left.\text { Gain }^{-1} \mathrm{cms}^{-1} \mathrm{mmHg}^{-1}\right) \\
\end{array}$ & $2.74(1.18)$ & $1.92(0.25)$ & \\
& & & \\
\hline
\end{tabular}

$* P<0.05$, steady-state versus oscillating LBNP

Table 5 Cross-spectral analysis during $0.1 \mathrm{~Hz}$ and $0.2 \mathrm{~Hz}$ LBNP oscillations. MAP was the input signal and CBFV was the output signal. The negative phase indicates that CBFV leads MAP. Gain is the MAP-CBFV gain. We assessed oscillations in the LF range, the $\mathrm{HF}$ breathing range $(0.25 \mathrm{~Hz})$ and the $\mathrm{HF}$ LBNP range $(0.20 \mathrm{~Hz})$

\begin{tabular}{|c|c|c|c|c|}
\hline & & $0.1 \mathrm{~Hz}$ & $0.2 \mathrm{~Hz}$ & $n$ \\
\hline LF & $\begin{array}{l}\text { Coherence } \\
\text { Phase (rad) } \\
\text { Gain }\left(\mathrm{cm} \mathrm{s}^{-1}\right. \\
\left.\mathrm{mmHg}^{-1}\right)\end{array}$ & $\begin{array}{l}0.77 \pm 0.05 \\
-1.27 \pm 0.18 \\
1.32 \pm 0.14\end{array}$ & $\begin{array}{l}0.66 \pm 0.04 \\
-1.28 \pm 0.12 \\
1.19 \pm 0.17\end{array}$ & 11 \\
\hline $\begin{array}{l}\mathrm{HF} \\
(0.25 \mathrm{~Hz})\end{array}$ & $\begin{array}{l}\text { Coherence } \\
\text { Phase (rad) } \\
\text { Gain }\left(\mathrm{cm} \mathrm{s}^{-1}\right. \\
\left.\mathrm{mmHg}^{-1}\right)\end{array}$ & $\begin{array}{l}0.87 \pm 0.04 \\
-0.16 \pm 0.08 \\
1.92 \pm 0.25\end{array}$ & $\begin{array}{l}0.90 \pm 0.02 \\
-0.12 \pm 0.07 \\
1.62 \pm 0.21\end{array}$ & 14 \\
\hline $\begin{array}{l}\mathrm{HF} \\
(0.20 \mathrm{~Hz})\end{array}$ & $\begin{array}{l}\text { Coherence } \\
\text { Phase (rad) } \\
\text { Gain }\left(\mathrm{cm} \mathrm{s}^{-1}\right. \\
\left.\mathrm{mmHg}^{-1}\right)\end{array}$ & & $\begin{array}{l}0.92 \pm 0.02 \\
-0.60 \pm 0.15 \\
2.05 \pm 0.32\end{array}$ & 16 \\
\hline
\end{tabular}




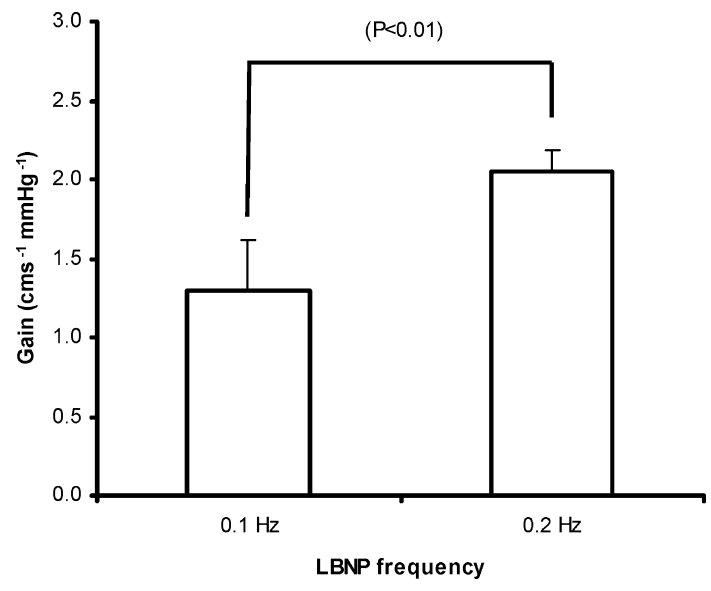

Fig. 3 Comparison of the effects of 0.1 and $0.2 \mathrm{~Hz}$ LBNP (0 to $-40 \mathrm{mmHg}$ ) stimulations on the CBFV-MAP gain at the stimulating frequency. The gain was significantly higher during $0.2 \mathrm{~Hz}$ LBNP, indicating an enhanced transmission of MAP oscillations onto the CBFV

\section{Discussion}

We found that cerebral autoregulation remains intact during steady-state orthostasis. However, when the stress is oscillatory, there is a reduction of the ability of the cerebral vessels to buffer fluctuations in perfusion pressure gradient and, possibly, $\mathrm{PCO}_{2}$. Furthermore, this effect seems to be enhanced when the frequency of the oscillatory stress is increased.

LBNP is associated with pooling of blood to the legs (Brown and Hainsworth 1999) and subsequent reductions in stroke volume and cardiac output (Baisch et al. 2000). Compensatory mechanisms mainly involve an increase in total peripheral vascular resistance (Brown and Hainsworth 2000) that is mediated by enhanced sympathetic outflow (Kimmerly and Shoemaker 2002; Levine et al. 2002). As in other studies (Cooke et al. 1999; Gulli et al. 2001), we found that MAP was well maintained during the steady-state orthostatic stress, with no change in the LF power of RR-interval oscillations but with an increase in the power of LF spontaneous blood pressure oscillations. The enhanced blood pressure oscillations were not transmitted onto the cerebral circulation, indicating that autoregulation protects the cerebral vessels from sympathetically mediated perturbations in blood pressure.

However, steady-state orthostasis is not a realistic simulation of the stresses encountered, for example, in a high performance aircraft where the gravitational forces might change rapidly. Therefore, we applied oscillatory LBNP to better replicate these stresses and to evaluate the regulation of cerebral blood flow when gravitational stress is applied at different frequencies. Oscillatory $0.1 \mathrm{~Hz}$ LBNP increased the power LF oscillations in MAP, but not by more than steady-state LBNP at the same level. This result demonstrates the importance of the arterial baroreflexes, which are most effective at regulating blood pressure when stimulated at around $0.1 \mathrm{~Hz}$ (Bernardi et al. 1997). Presumably, the $0.1 \mathrm{~Hz}$ LBNP oscillations were counteracted to some extent by baroreflex-mediated adjustments of vascular resistance. However, steady-state and oscillatory LBNP had considerably different effects on CBFV. LBNP at $0.1 \mathrm{~Hz}$ applied at 0 to $-40 \mathrm{mmHg}$ induced a significant increase in the magnitude of LF oscillations in CBFV whereas constant LBNP at $-40 \mathrm{mmHg}$ did not. This effect was also manifested by an increase in the MAP-CBFV gain during oscillatory LBNP. These findings suggest a deterioration of cerebral autoregulation during oscillatory compared to steady-state LBNP.

As in other studies (Cencetti et al. 1999; Diehl et al. 1995; Hughson et al. 2001), we found that the CBFV oscillations led the oscillations in blood pressure. This phase-relation can be explained by the time-lag by which cerebrovascular resistance responds to changes in cerebral perfusion pressure (Hughson et al. 2001). Our finding that there was no difference in the MAP-CBFV phase shift during $0.1 \mathrm{~Hz}$ oscillatory compared with steady-state LBNP suggests no change in the timecourse of the autoregulatory response despite the reduced buffering ability of the cerebral vessels during oscillatory LBNP.

The higher gain of MAP oscillations onto the CBFV during $0.2 \mathrm{~Hz}$ oscillatory LBNP suggests that the buffering ability of the cerebral vessels is even more impaired during HF fluctuations in blood pressure. This concept is also supported by the large gain of $\mathrm{HF}$ breathing-induced oscillations onto the CBFV. Our study confirms that externally induced HF MAP oscillations by LBNP are similarly imposed onto the CBFV. These findings are therefore consistent with the hypothesis that cerebral autoregulation acts as a highpass filter, whereby LF oscillations in blood pressure are buffered but HF oscillations $(>0.15 \mathrm{~Hz})$ are more readily transferred onto the cerebral vessels (Diehl et al. 1995). Hughson et al (2001) showed that cyclical changes in cerebral perfusion pressure, elicited by repeated headup tilting at $0.1 \mathrm{~Hz}$, were followed by changes in cerebrovascular resistance in order to maintain CBFV near-constant. We assume that even faster oscillations in blood pressure, in the HF range, are too rapid for adjustment of the cerebrovascular resistance. The mechanisms behind these autoregulatory mechanisms remain a matter for speculation but are probably a combination of metabolic, myogenic and neurohormonal factors (Faraci and Heistad 1998; Olesen 1972).

A limitation of our study is that we did not replicate a true "push-pull" effect such as that experienced on board a high-performance aircraft because we only simulated $+\mathrm{Gz}$ by LBNP, rather than variation between $+\mathrm{Gz}$ and $-\mathrm{Gz}$. Although our results do show the effects of different stimulating frequencies on cerebral autoregulation, further studies might be necessary to give a greater insight into the complete push-pull effect.

Another methodological point concerns the use of transcranial Doppler for measurements of cerebral 
blood flow. The assumption that changes in CFBV reflect changes in cerebral blood flow depends on the diameter of the insonated portion of the mid-cerebral artery remaining constant. There is ample evidence that the diameter of the mid-cerebral artery does not change during rapid alterations in arterial pressure (Newell et al. 1994) and during LBNP (Serrador et al. 2000a). We are therefore confident that the changes in CBFV that we measured reflect actual changes in cerebral blood velocity and were not influenced by changes in the diameter of the insonated artery.

We must also consider that there are two other potential mechanisms that could influence the interpretation of the current data. Firstly, a decrease in $\mathrm{CO}_{2}$ during orthostasis has been observed before (Cencetti et al. 1997; Hughson et al. 2001; Serrador et al. 2000b) and might be attributed to changes in the ventilationperfusion ratio at the lung (Cencetti et al. 1997). The fluctuations in $\mathrm{CO}_{2}$ that we found during the oscillating LBNP might have contributed to an increased gain of blood pressure oscillations onto the CBFV. However, the time-constant for $\mathrm{CO}_{2}$ reactivity on the cerebral vasculature is around $20 \mathrm{~s}$ (Ursino and Lodi 1998). Neither can we exclude that our CBFV results could also have been influenced by changes in venous pressure. This factor might be important because CBFV is also a function of the arterial-venous pressure gradient. It is likely that the LBNP oscillations also induced an oscillation in venous pressure thus altering the cerebral perfusion pressure gradient. During orthostasis, the cerebral vessels might be held open due to their containment in the cerebral sinuses and thereby act as a "siphon" which decreases venous pressure and potentially maintains perfusion pressure (Gauer and Thron 1965).

\section{Summary}

Although the cerebral vessels can dampen physiological LF blood pressure fluctuations during steady-state orthostasis, this modulation is reduced when the orthostatic stress is fluctuating. Furthermore, this effect becomes even more pronounced at higher frequencies of orthostatic stress oscillations. These findings could therefore be of relevance in situations where the fluctuations in gravitational forces might be large enough to induce syncope. While our results might be explained by the traditional concepts of cerebral autoregulation, other factors such as changes in arterial $P C_{2}$ require further study.

\section{References}

Aaslid R, Lindegaard KF, Sorteberg W, Nornes H (1989) Cerebral autoregulation dynamics in humans. Stroke 20:45-52

Baisch F, Beck L, Blomqvist G, Wolfram G, Drescher J, Rome JL, Drummer C (2000) Cardiovascular response to lower body negative pressure stimulation before, during, and after space flight. Eur J Clin Invest 30:1055-1065

Banks RD, Grissett JD, Turnipseed GT, Saunders PL, Rupert AH (1994) The "push-pull effect". Aviat Space Environ Med 65:699-704

Bernardi L, Bianchini B, Spadacini G, Leuzzi S, Valle F, Marchesi E, Passino C, Calciati A, Vigano M, Rinaldi M, Martinelli L, Finardi G, Sleight P (1995) Demonstrable cardiac reinnervation after human heart transplantation by carotid baroreflex modulation of RR interval. Circulation 92:2895-2903

Bernardi L, Hayoz D, Wenzel R, Passino C, Calciati A, Weber R, Noll G (1997) Synchronous and baroceptor-sensitive oscillations in skin microcirculation: evidence for central autonomic control. Am J Physiol 273:H1867-H1878

Birch AA, Dirnhuber MJ, Hartley-Davies R, Iannotti F, NeilDwyer G (1995) Assessment of autoregulation by means of periodic changes in blood pressure. Stroke 26:834-837

Brown CM, Hainsworth R (1999) Assessment of capillary fluid shifts during orthostatic stress in normal subjects and subjects with orthostatic intolerance. Clin Auton Res 9:69-73

Brown CM, Hainsworth R (2000) Forearm vascular responses during orthostatic stress in control subjects and patients with posturally related syncope. Clin Auton Res 10:57-61

Brown CM, Dütsch M, Michelson G, Neundörfer B, Hilz MJ (2002) Impaired cardiovascular responses to baroreflex stimulation in open-angle and normal-pressure glaucoma. Clin Sci 102:623-630

Carey BJ, Manktelow BN, Panerai RB, Potter JF (2001) Cerebral autoregulatory responses to head-up tilt in normal subjects and patients with recurrent vasovagal syncope. Circulation 104:898902

Cencetti S, Bandinelli G, Lagi A (1997) Effect of PCO2 changes induced by head-upright tilt on transcranial Doppler recordings. Stroke 28:1195-1197

Cencetti S, Lagi A, Cipriani M, Fattorini L, Bandinelli G, Bernardi L (1999) Autonomic control of the cerebral circulation during normal and impaired peripheral circulatory control. Heart $82: 365-372$

Cooke WH, Hoag JB, Crossman AA, Kuusela TA, Tahvanainen KU, Eckberg DL (1999) Human responses to upright tilt: a window on central autonomic integration. J Physiol 517:617-628

Diehl RR, Linden D, Lucke D, Berlit P (1995) Phase relationship between cerebral blood flow velocity and blood pressure. A clinical test of autoregulation. Stroke 26:1801-1804

Faraci FM, Heistad DD (1998) Regulation of the cerebral circulation: role of endothelium and potassium channels. Physiol Rev 78:53-97

Gauer OH, Thron HL (1965) Postural changes in the circulation. In: Hamilton WF, Dow P (eds) Handbook of physiology, Section 2, vol III. American Physiological Society, Baltimore, Md.

Gulli G, Wight VL, Hainsworth R, Cevese A (2001) Spectral and cross-spectral autoregressive analysis of cardiovascular variables in subjects with different degrees of orthostatic tolerance. Clin Auton Res 11:19-27

Heckmann JG, Hilz MJ, Hagler H, Muck-Weymann M, Neundorfer B (1999) Transcranial Doppler sonography during acute 80 degrees head-down tilt (HDT) for the assessment of cerebral autoregulation in humans. Neurol Res 21:457-462

Heckmann JG, Hilz MJ, Muck-Weymann M, Neundorfer B (2000) Transcranial doppler sonography-ergometer test for the noninvasive assessment of cerebrovascular autoregulation in humans. J Neurol Sci 177:41-47

Hughson RL, Edwards MR, O'Leary DD, Shoemaker JK (2001) Critical analysis of cerebrovascular autoregulation during repeated head-up tilt. Stroke 32:2403-2408

Kimmerly DS, Shoemaker JK (2002) Hypovolemia and neurovascular control during orthostatic stress. Am J Physiol 282:H645-H655

Levine BD, Pawelczyk JA, Ertl AC, Cox JF, Zuckerman JH, Diedrich A, Biaggioni I, Ray CA, Smith ML, Iwase S, Saito M, Sugiyama Y, Mano T, Zhang R, Iwasaki K, Lane LD, Buckey JC Jr., Cooke WH, Baisch FJ, Eckberg DL, Blomqvist CG 
(2002) Human muscle sympathetic neural and haemodynamic responses to tilt following spaceflight. J Physiol 538:331-340

Lipsitz LA, Mukai S, Hamner J, Gagnon M, Babikian V (2000) Dynamic regulation of middle cerebral artery blood flow velocity in aging and hypertension. Stroke 31:1897-1903

Newell DW, Aaslid R, Lam A, Mayberg TS, Winn HR (1994) Comparison of flow and velocity during dynamic autoregulation testing in humans. Stroke 25:793-797

Olesen J (1972) The effect of intracarotid epinephrine, norepinephrine, and angiotensin on the regional cerebral blood flow in man. Neurology 22:978-987

Pitzalis MV, Mastropasqua F, Passantino A, Ligurgo L, Forleo C, Balducci C, Lombardi F, Rizzon P (1998) Comparison between noninvasive methods indices of baroreceptor sensitivity and the phenylephrine method in post-myocardial infarction patients. Circulation 97:1362-1367

Schlegel TT, Brown TE, Wood SJ, Benavides EW, Bondar RL, Stein F, Moradshahi P, Harm DL, Fritsch-Yelle JM, Low PA
(2001) Orthostatic intolerance and motion sickness after parabolic flight. J Appl Physiol 90:67-82

Serrador JM, Picot PA, Rutt BK, Shoemaker JK, Bondar RL (2000a) MRI measures of middle cerebral artery diameter in conscious humans during simulated orthostasis. Stroke 31:1672-1678

Serrador JM, Shoemaker JK, Brown TE, Kassam MS, Bondar RL, Schlegel TT (2000b) Cerebral vasoconstriction precedes orthostatic intolerance after parabolic flight. Brain Res Bull 53:113120

Tiecks FP, Douville C, Byrd S, Lam AM, Newell DW (1996) Evaluation of impaired cerebral autoregulation by the Valsalva maneuver. Stroke 27:1177-1182

Ursino M, Lodi CA (1998) Interaction among autoregulation, CO2 reactivity, and intracranial pressure: a mathematical model. Am J Physiol 274: H1715-H1728 